\title{
STUDY OF BODE INDEX AS A PREDICTOR OF HOSPITALISATION IN PATIENTS WITH COPD
}

\author{
Bonny Pullolil James ${ }^{1}$, Vivek Sathyaseelan², Jineesh Joseph ${ }^{3}$
}

${ }_{1}^{1}$ Assistant Professor, Department of Pulmonology, Al-Azhar Medical College and Super Speciality Hospital, Thodupuzha, Kerala, India. ${ }^{2}$ Assistant Professor, Department of Community Medicine, Al-Azhar Medical College and Super Speciality Hospital, Thodupuzha, Kerala, India.

3Senior Resident, Department of Pulmonology, Al-Azhar Medical College and Super Speciality Hospital, Thodupuzha, Kerala, India. ABSTRACT

\section{BACKGROUND}

Chronic Obstructive Pulmonary Disease (COPD) is a common preventable and treatable disease. WHO estimates that it will be the fifth leading cause of disability and the fourth leading cause of death by the end of 2030. Recently, a multidimensional grading system based on the Body Mass Index (B), Degree of Airflow Obstruction (O), Dyspnoea (D) and Exercise Capacity (E) - the BODE Index - has begun to be used increasingly for the evaluation of COPD patients.

\section{MATERIALS AND METHODS}

It is a prospective observational study conducted in Al-Azhar Medical College during the period of January 2015 to February 2016.

\section{RESULTS}

Among patients with COPD, 9 patients (18\%) stayed in hospital for more than 8 days. 31 (62\%) of them stayed between 5 - 7 days, whereas $10(20 \%)$ stayed in hospital for less than 4 days. Also, the study results show that $40(80 \%)$ patients were readmitted in hospital within 1 - 6 months of duration, 6 (12\%) were readmitted within a month or less than a month and 4 (8\%) were readmitted after 6 months only for the same symptoms.

\section{CONCLUSION}

The study could not reveal a significant correlation between BODE index and duration of hospital stay. But it revealed that BODE index is a very good predictor of frequency of hospital readmission rates.

\section{KEY WORDS}

COPD, BODE Index.

HOW TO CITE THIS ARTICLE: James BP, Sathyaseelan V, Joseph J. Study of bode index as a predictor of hospitalisation in patients with COPD. J. Evolution Med. Dent. Sci. 2018;7(32):3625-3628, DOI: 10.14260/jemds/2018/814

\section{BACKGROUND}

COPD is a slowly progressive disorder characterised by airflow obstruction that is not fully reversible.(1) COPD is a major cause of morbidity and mortality throughout the world. The prevalence and burden of COPD are projected to increase in the coming decades due to continued exposure to COPD risk factors and the changing age structure of the world's population. It is projected to fifth leading cause of disability and the fourth leading cause of death by the end of 2030 according to a study published by the World Health Organisation.[2] Although, the progression of COPD is usually gradual, the disease is often associated with exacerbations of respiratory symptoms. Such exacerbations of symptoms requiring medical intervention are important clinical events in COPD and they place a heavy burden on health-care resources. In many countries, exacerbations of COPD are a leading cause of hospital admissions among men and expenditures for hospitalisations represent the bulk of all COPD-related medical-care costs.(3) The disease causes a heavy burden on the global health care resources. Studies

'Financial or Other Competing Interest': None.

Submission 20-04-2018, Peer Review 01-06-2018,

Acceptance 08-06-2018, Published 06-08-2018.

Corresponding Author:

Dr. Vivek Sathyaseelan,

Al-Azhar Medical College,

Ezhaloor, Thodupuzha-685605,

Idukki-District, Kerala, India.

E-mail: ps.vivekdr@gmail.com

DOI: $10.14260 /$ jemds $/ 2018 / 814$

\section{(c) (i) $\odot$}

suggest that factors other than the degree of airflow obstruction may influence the frequency of hospitalisation for COPD, and a multidimensional grading system that assesses the respiratory and systemic manifestations of COPD would thus categorise and predict this outcome better than a classification of disease severity based on FEV1 alone. In a case-control study(4) of a wide range of potential risk factors, lower FEV1 was one of the several factors found to be independently associated with a higher risk of admission for a COPD exacerbation. Recently, the BODE (Body mass index, airflow obstruction, dyspnoea and exercise capacity) index, a multidimensional grading system, was shown to be better than FEV1 in predicting the morbidity among patients with COPD. This multistage scoring system that incorporates an assessment of symptoms, nutritional state and exercise capacity together with the spirometric measure of airflow (FEV1) can provide useful prognostic information in patients with COPD.

\section{Aims and Objectives}

1. To determine whether higher BODE index is associated with duration of hospitalisation.

2. To determine whether higher BODE index correlates with frequency of hospital readmission.

\section{MATERIALS AND METHODS} Study Population 
Study was conducted in 50 cases of COPD in Al-Azhar Medical College and super specialty hospital, Ezhaloor, Thodupuzha during the period of January 2015 to February 2016.

\section{Study Design}

It was a prospective observational study and this study was conducted after obtaining ethical clearance from Ethical Committee of medical college.

\section{Inclusion Criteria}

Patients aged between 40 - 70 years with symptoms suggestive of COPD were assessed with spirometry. The values of Forced Expiratory Volume in first second (FEV1) less than $80 \%$ of the expected value and ratio of forced expiratory volume in first second to the forced vital capacity less $\left(\mathrm{FEV}_{1} \%\right)$ than $0.7(70 \%)$ after post-bronchodilator inhalation were included in this study.

\section{Exclusion Criteria}

1. Spirometry proved bronchial asthma.

2. Patient having drop in saturation to $<90 \%$ on 6 -minute walk test.

3. Patient on long-term oxygen therapy.

4. Patient unable to perform 6-metre walk test (6-MWT) and spirometry.

5. Recent myocardial infarction $<4$ months.

6. Unstable angina.

7. Congestive heart failure (NYHA class III or II).

8. Female patients.

\section{Statistical Analysis}

Data were entered and analysed using SPSS software for Windows version 20.0. Results were described in the form of mean and standard deviation, frequency and proportions. Association between variables was tested using Chi-square test and $p$ value of $<0.05$ was considered significant.

\section{RESULTS}

The present analysis was restricted to male patients only. For each enrolled subject, detailed history of smoking, personal and medical histories were obtained. On the day of enrolment, height and weight were measured. Body Mass Index (BMI) was calculated by the formula. BMI= Weight in Kgs/ (Height in Metre). ${ }^{2}$ Spirometry was performed with equipment that met the American Thoracic Society Performance criteria, in each of the cases on enrolment into the study and 20 minutes following the administration of salbutamol nebulisation. Forced expiratory volume in 1 second (FEV1) and forced vital capacity (FVC) were calculated. Ratio between FEV1 and FVC were calculated. A detailed history of the dyspnoea experienced by the patient were taken. MMRC dyspnoea scale was used to score patient's dyspnoea. Six minute walk test was performed twice with a gap of 30 minutes rest in between. Patients were asked to walk on a level ground for maximum possible distance within the duration of 6 minutes. Periods of rest taken was also included in the 6 minutes test period. The best of two 6-mins walk tests performed at least 30-mins apart(5) was used for scoring. The BODE index was calculated for each patient using the body mass index, the threshold value of FEV1, the distance walked in 6 mins and the score on the Modified
Medical Research Council (MMRC) dyspnoea scale. The patients received points ranging from 0 (lowest value) to 3 (maximal value). For body mass index, the values were 0 $(>21)$ or $1(<21)$. The scores for FEV1 were 0 (more than or equal to 65\%), 1 (50 - 64\%), 2 (36-49\%) and 3 (less than or equal to $35 \%$ ). The 6 -minute walk test scores were 0 ( $>350$ $\mathrm{mts}$ ), 1 (250 - $350 \mathrm{mts}$ ), 2 (150 - $249 \mathrm{mts})$ and 3 (< $150 \mathrm{mts}$ ). The MMRC dyspnoea class 0 and I were given 0 points, class II -1 point, class III -2 points and class IV -3 points. The points for each variable were added, so that the BODE index ranged from 0 to 10 points in each patient. The BODE score of $0-2$ was taken as mild COPD. Scores between $3-5$ was considered as moderate disease and those more than or equal to 6 was considered as severe COPD.

\begin{tabular}{|c|c|c|c|c|}
\hline Bode Score & $\mathbf{0}$ & $\mathbf{1}$ & $\mathbf{2}$ & $\mathbf{3}$ \\
\hline FEV1 & $>65 \%$ & $50-64 \%$ & $36-49 \%$ & $<35 \%$ \\
\hline $\begin{array}{c}6 \text { mins walk } \\
\text { test }\end{array}$ & $>350 \mathrm{mtrs}$ & $\begin{array}{c}250-349 \\
\mathrm{mtrs}\end{array}$ & $\begin{array}{c}150-249 \\
\mathrm{mtrs}\end{array}$ & $<149 \mathrm{mtrs}$ \\
\hline $\begin{array}{c}\text { Dyspnoea } \\
\text { scale }\end{array}$ & $0-1$ & 2 & 3 & 4 \\
\hline BMI & $>21 \mathrm{~kg} / \mathrm{m} 2$ & $<21 \mathrm{~kg} / \mathrm{m} 2$ & & 4 \\
\hline \multicolumn{5}{|c|}{ Table 1. BODE Variables and Scoring } \\
\hline
\end{tabular}

Coding system was used for both Hospital stay and Hospital readmission. Coding zero was used for hospital stay less than or equal to 4 days, coding one for 5 to 7 days of hospitalisation and coding two for hospital stay more than or equal to 8 days. For hospital readmission duration coding zero was used to denote patients who are readmitted within first month, coding one for patients readmitted within a period of one to six months and coding two for patients readmitted after six months.

A total of 50 patients were enrolled in the study. Among patients with COPD, there were $8(16 \%)$ patients who had mild COPD with a BODE score between 0 - 2. Moderate (BODE score of 3 - 5) was seen in 21 (42\%) patients and severe COPD (BODE score more than or equal to 6) was seen in 21 (42\%) patients each.

\begin{tabular}{|c|c|c|c|}
\hline Bode Index & Frequency & $\mathbf{\%}$ & Cumulative \% \\
\hline 0 (Mild) & 8 & 16.0 & 16.0 \\
\hline 1 (Moderate) & 21 & 42.0 & 58.0 \\
\hline 2 (Severe) & 21 & 42.0 & 100.0 \\
\hline Total & $\mathbf{5 0}$ & $\mathbf{1 0 0 . 0}$ & \\
\hline \multicolumn{4}{|c|}{ Table 2. Bode Index } \\
\hline
\end{tabular}

Relation between Bode Index and Duration of Hospital Stay

Among patients with COPD, there were 9 patients (18\%) who stayed in hospital for more than 8 days. 31 (62\%) were stayed between 5 - 7 days, whereas $10(20 \%)$ stayed in hospital for less than 4 days.

\begin{tabular}{|c|c|c|c|}
\hline Hospital Stay & Frequency & $\mathbf{\%}$ & Cumulative \% \\
\hline Less than 4 days & 10 & 20.0 & 20.0 \\
\hline 5 - 7 days & 31 & 62.0 & 82.0 \\
\hline $\begin{array}{c}\text { More than } 8 \\
\text { days }\end{array}$ & 9 & 18.0 & 100.0 \\
\hline
\end{tabular}




\begin{tabular}{|c|c|c|c|}
\hline Total & 50 & 100.0 & \\
\hline \multicolumn{3}{|c|}{ Table 3. Duration of Hospital Stay } \\
\hline
\end{tabular}

\begin{tabular}{|c|c|c|c|c|c|}
\hline \multirow{2}{*}{\multicolumn{2}{|c|}{ Hospital Stay }} & \multicolumn{3}{|c|}{ BODE Index } & \multirow{3}{*}{$\begin{array}{c}\text { Total } \\
10 \\
\end{array}$} \\
\hline & & \multirow{2}{*}{\begin{tabular}{|l|}
$\mathbf{0}$ \\
3 \\
\end{tabular}} & \multirow{2}{*}{1} & \multirow{2}{*}{\begin{tabular}{|l|}
$\mathbf{2}$ \\
2 \\
\end{tabular}} & \\
\hline \multirow[b]{2}{*}{ (Less than 4 days) } & \multirow[b]{2}{*}{0} & & & & \\
\hline & & $30.0 \%$ & $50.0 \%$ & $20.0 \%$ & $100.0 \%$ \\
\hline \multirow{2}{*}{ (5 - 7 days) } & \multirow[b]{2}{*}{1} & \begin{tabular}{|l|}
5 \\
\end{tabular} & 14 & 12 & 31 \\
\hline & & $16.1 \%$ & $45.2 \%$ & $38.7 \%$ & $100.0 \%$ \\
\hline \multirow{2}{*}{ More than 8 days } & \multirow{2}{*}{2} & \begin{tabular}{|l|}
0 \\
\end{tabular} & 2 & 7 & 9 \\
\hline & & $0.0 \%$ & $22.2 \%$ & $77.8 \%$ & $100.0 \%$ \\
\hline \multirow{2}{*}{\multicolumn{2}{|c|}{$10 \mathrm{de}$}} & \begin{tabular}{|l|l}
8 \\
\end{tabular} & 21 & 21 & 50 \\
\hline & & $16.0 \%$ & $42.0 \%$ & $42.0 \%$ & $100.0 \%$ \\
\hline \multicolumn{2}{|l|}{ P value } & \multicolumn{4}{|c|}{$0.103^{*}$} \\
\hline \multicolumn{6}{|c|}{$\begin{array}{l}\text { Table 4. Association between duration of Hospital } \\
\text { Stay and BODE Index }\end{array}$} \\
\hline
\end{tabular}

The study results showed that a higher BODE score was not associated with a longer hospital stay due to reasons related to COPD ( $\mathrm{p}$ value is 0.103 ).

\section{Relation between Bode Index and duration between Hospital Readmission}

The study results show that 40 (80\%) patients were readmitted in hospital within 1 - 6 months of duration, 6 $(12 \%)$ were readmitted within a month or less than a month and $4(8 \%)$ were readmitted after 6 months only for the same symptoms.

\begin{tabular}{|c|c|c|c|}
\hline $\begin{array}{c}\text { Gap between } \\
\text { Readmission }\end{array}$ & Frequency & $\mathbf{\%}$ & Cumulative \% \\
\hline $0(<1$ month $)$ & 6 & 12.0 & 12.0 \\
\hline $1(1-6$ month $)$ & 40 & 80.0 & 92.0 \\
\hline $2(>6$ month $)$ & 4 & 8.0 & 100.0 \\
\hline Total & $\mathbf{5 0}$ & $\mathbf{1 0 0 . 0}$ & \\
\hline \multicolumn{4}{|c|}{ Table 5. Gap between Readmission } \\
\hline
\end{tabular}

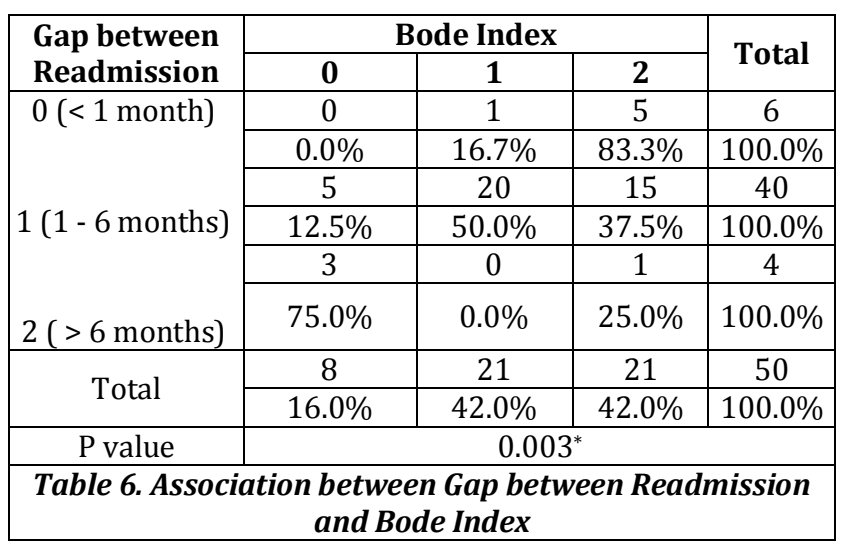

The study results showed that a higher BODE score was associated with gap between readmission in hospital due to reasons related to COPD ( $\mathrm{p}$ value is 0.003 ).

\section{DISCUSSION}

In the recent past, more stress has been given to formulate a simple but effective index for assessing the severity of COPD. Researchers have found that BODE index would fulfil this necessity. In our study, we tried to evaluate its usefulness in predicting the severity of COPD in terms of duration of hospitalisation and frequency of hospital readmission. The main finding of this study is that the BODE staging system,(6) which includes in addition to FEV1 other physiologic and clinical variables, helps to better predict hospitalisation in patients with COPD. COPD is a complex multidimensional disease and classification schemes that incorporate more parameters than the degree of airflow obstruction are likely to predict outcomes more accurately.(7) FEV1 is known to correlate poorly with symptoms, ${ }^{(8)}$ quality of life, 16 exacerbation frequency ${ }^{(9)}$ and exercise intolerance.(10) Hence, newer approaches to disease assessment are required and may even supersede the current FEV1-based system of classification of disease severity.(11) The multistage scoring system used in this study incorporates variables that can be easily evaluated in any office setting and the BODE index has potential widespread applicability just like the FEV1. Important to the acceptance for use of this new classification system is the evidence to support that it provides more useful prognostic information than FEV1 alone. The multidimensional staging system of the BODE index has already been shown to be a superior predictor of morbidity in COPD patients compared to the FEV1-based staging system by the ATS.(6) Additionally, the BODE index is also responsive to changes resulting from exacerbations and may capture the impact of exacerbations in patients with COPD.(12) In this study, we were able to replicate the finding of the BODE index being a better predictor of morbidity than the FEV1. The BODE index was also reported to be a much better predictor of the severity in COPD acute exacerbations than FEV1.(6,13) Additionally, the BODE index is also responsive to changes resulting from exacerbations and may capture the impact of exacerbations in patients with COPD. Our findings of the usefulness of the BODE index in predicting hospitalisation for COPD are also supported by the findings of a prospective study(14) of risk factors of hospital readmissions for COPD exacerbation. Admission to the hospital and heavy use of healthcare resources is a common feature of COPD. As the BODE index can provide useful prognostic information of survival and hospitalisation, the findings of the present study are in support of the utility of the BODE index as an assessment tool for COPD patients.(7) The study could not reveal a significant correlation between BODE index and duration of hospital stay may be due to low sample size. But it revealed that BODE index is a very good predictor of frequency of hospital readmission rates. In summary the BODE scoring system is a better predictor of hospitalisation for COPD than the staging criteria based largely on FEV1. These findings are in support of the use of the BODE scoring system as a practical instrument for outcomes of assessment in COPD.

\section{Limitations of the Study}

1. I would like to acknowledge that a relatively small number of patients were evaluated and that the number of patients required to detect a significant difference in the predictive power of the BODE index and FEV1 have not been prospectively determined.

2. The study is a hospital based study and may not be representative of the general population.

3. Only males were inducted into the study. Hence, the results of the study cannot be used in female patients with COPD. 
4. Alternate causes and medication effects influencing the parameters analysed should also be considered.

\section{CONCLUSION}

One clinical implication of the present study is that the BODE scoring system may prove to be helpful in health-care resource allocation and in guiding therapy for individual patients in the future. This multistage scoring system, which incorporates variables that can be evaluated easily in any office setting should not be difficult or costly to implement routinely. In summary, the BODE scoring system is a better predictor of hospitalisation for COPD than the staging criteria based largely on FEV1.

\section{REFERENCES}

[1] The Gold reports 2017. Global strategy for the diagnosis, management and prevention of COPD 2017. www. goldcopd.com.

[2] National Heart, Lung and Blood Institute. Morbidity and mortality chart book on cardiovascular, lung and blood diseases. Bethesda, Maryland: US Department of Health and Human Services, Public Health Service, National Institute of Health. 2004. http://www.nhlbi.nih.gov/ resources/ docs/chtbook.html

[3] Sullivan SD, Ramsey SD, Lee TA. The economic burden of COPD. Chest 2000;117(Suppl 2):5S-9S.

[4] Garcia-Aymerich J, Monso' E, Marrades RM, et al. Risk factors for hospitalization for a chronic obstructive pulmonary disease exacerbation. EFRAM Study. Am J Respir Crit Care Med 2001;164(6):1002-7.

[5] ATS Committee on Proficiency Standards for Clinical Pulmonary Function Laboratories. ATS statement: guidelines for the six-minute walk test. Am J Respir Crit Care Med 2002;166(1):111-7.
[6] Celli BR, Cote CG, Marin JM, et al. The body mass index, airflow obstruction, dyspnea and exercise capacity index in chronic obstructive pulmonary disease. N Engl J Med 2004;350(10):1005-12.

[7] Rennard SI. Looking at the patient: approaching the problem of COPD. N Engl J Med 2004;350(10):965-6.

[8] Mahler DA, Weinberg DH, Wells CK, et al. The measurement of dyspnea. Contents, inter-observer agreement and physiologic correlates of two new clinical indexes. Chest 1984;85(6):751-8.

[9] Alsaeedi A, Sin DD, McAlister FA. The effects of inhaled corticosteroids in chronic obstructive pulmonary disease: a systematic review of randomized placebocontrolled trials. Am J Med 2002;113(1):59-65.

[10] O'Donnell DE, Lam M, Webb KA. Measurement of symptoms, lung hyperinflation and endurance during exercise in chronic obstructive pulmonary disease. Am J Respir Crit Care Med 1998;158(5 Pt 1):1557-65.

[11] Calverley PMA. The GOLD classification has advanced understanding of COPD. Am J Respir Crit Care Med 2004;170(3):211-4.

[12] Boman C, Forsberg B, Sandstrom T. Shedding new light on wood smoke: a risk factor for respiratory health. Eur Respir J 2006;27(3):446-7.

[13] Marin JM, Carrizo SJ, Casanova C, et al. Prediction of risk of COPD exacerbation by the BODE index. Respir Med 2009;103(3):373-8. www.resmedjournal.com

[14] Garcia-Aymerich J, Farrero E, Fe'lez MA, et al. Risk factors of readmission to hospital for a COPD exacerbation: a prospective study. Thorax 2003;58(2):100-5. 